Debt Servicing, Aggregate Consumption, and Growth

Mark Setterfield and Yun K. Kim

WORKING PAPER 2014-10

DEPARTMENT OF ECONOMICS

UNIVERSITY OF MASSACHUSETTS BOSTON 


\title{
Debt Servicing, Aggregate Consumption, and Growth*
}

\author{
Mark Setterfield ${ }^{\dagger}$ and Yun K. Kim ${ }^{\ddagger}$
}

\begin{abstract}
We develop a neo-Kaleckian growth model that emphasizes the importance of consumption behavior. In our model, workers first make consumption decisions based on their gross income, and then treat debt servicing commitments as a substitute for saving. Workers' borrowing is induced by their desire to keep up with the consumption standard set by rentiers' consumption, reflecting an aspect of the relative income hypothesis. As a result of this consumption and debt servicing behavior, consumer debt accumulation and income distribution have effects on aggregate demand, profitability, and economic growth that differ from those found in existing models. We also investigate the financial sustainability of the Golden Age and Neoliberal growth regimes within our framework. It is shown that distributional changes between the Golden Age and the Neoliberal regimes, together with corresponding changes in consumption emulation behavior via expenditure cascades, suffice to make the Neoliberal growth regime unsustainable.
\end{abstract}

Key words: Consumer debt, emulation, income distribution, Golden Age regime, Neoliberal regime, expenditure cascades, growth

JEL classifications: E12, E44, O41

\section{Introduction}

In a Kalecki-Keynes world, investment drives saving with an appropriately functioning financial market, rather than saving driving investment as in orthodox theory. Making the

*Earlier versions of this paper were presented at the meetings of the Eastern Economic Association, New York, May 2013, the FESSUD Annual Conference "Financialisation and the Financial Crisis", Amsterdam, October 2013, and the $17^{\text {th }}$ FMM Conference "The Jobs Crisis: Causes, Cures, Constraints", Berlin, October 2013. The authors would like to thank conference participants, Barry Cynamon, Steve Fazzari, Eckhard Hein, and Soon Ryoo for their helpful comments. Any remaining errors are our own. Mark Setterfield would like to thank the Institute for New Economic Thinking for generous financial support that facilitated his work on this paper.

${ }^{\dagger}$ Department of Economics, New School For Social Research, New York, NY 10003 and Trinity College, Hartford; setterfm@newschool.edu

${ }^{\ddagger}$ Department of Economics, University of Massachusetts Boston, Boston, MA 02125 yun.kim@umb.edu. 
Keynes-Kalecki assumption that output is endogenous to investment, the output level is an adjustment variable for generating an appropriate (investment-expenditure-equalizing) level of savings. In other words, savings - and hence consumption - are largely passive/residual variables in the Kalecki-Keynes framework.

However, this neglects the point that consumption has become an important independent source of aggregate demand in the macroeconomy. The active role of consumption has been made possible by the increased availability of consumer credit in an increasingly consumerfriendly culture. ${ }^{1}$ A well functioning financial sector is an important precondition for the independence of investment from saving in Kalecki and Keynes. In Joan Robinson's words, it is "the central thesis of the General Theory, that firms are free, within limits, to accumulate as they please, and that the rate of saving of the economy as a whole accommodates itself to the rate of investment that they decree" (Robinson (1962, p.82-83) quoted in Asimakopulos (1983)). In more recent times, characterized by easily accessible consumer credit, a rather crude but similar statement can now be made about aggregate consumption: "[households] are free, within wide limits, to [consume] as they please, and ... the rate of saving of the economy as a whole accommodates itself to the rate of [consumption] that they decree."

But if credit facilitates autonomous consumption, what actually causes household spending to become disconnected from household income? In keeping with the insights of the relative income hypothesis (Duesenberry, 1949), one source of this disconnect is the propensity of households to emulate contemporary standards of consumption established by others. Cynamon and Fazzari (2008, 2013), for example, provide a detailed explanation of this behavior based on the notion that consumer preferences endogenously evolve in a world of social cues. This gives rise to a situation in which households use credit and debt to consume in excess of what their current income and wealth allow, in the pursuit of consumption standards set by other (more affluent) households. In a decision-making environment of fundamental uncertainty, it is unlikely that households always fully understand the future consequences

\footnotetext{
${ }^{1}$ For discussion of the non-economic factors associated with these developments, see Schor (1998), Cynamon and Fazzari (2008, 2013), and Wisman (2009, 2013).
} 
of this behavior.

Inequality also affects consumption and household debt accumulation. According to Barba and Pivetti (2009), there have been substantial shifts in income away from low and middle-income classes in the US since the 1980s, accompanied by a large drop in the personal saving rate, massive increases in household liabilities, and large increases in the use of household debt to finance consumption in the bottom 80 percent of the income distribution. Barba and Pivetti (2009) argue that rising household debt has largely been caused by the efforts of low and middle-income households to maintain their relative standards of consumption in the face of persistent changes in the income distribution that have favored higher income households. ${ }^{2}$

In light of the preceding discussion, we believe it is important to reexamine the macroeconomic implications of consumption and saving decisions and household debt accumulation. Reflecting this concern, we propose a macroeconomic model that features not only an independent investment function, but also a consumption function in which explicitly modeled borrowing by some households, motivated by a desire to emulate the consumption standards of more affluent households, finances part of total household consumption expenditure. We are, of course, by no means the first to consider such extensions of the Keynes-Kalecki view (see, for example, Dutt (2005, 2006, 2008); Kim (2012)). But the analysis that follows makes three important contributions to the existing literature. First, building on the work of Kim et al. (Forthcoming), we show that the precise manner in which debtor households manage their debt servicing commitments (rather than simply whether or not debt servicing commitments exist and increase over time) affects the characteristics of the growth regime. Second, by focusing on the relationship between changes in income distribution and the debt dynamics of our model, we isolate the important role that increasing income inequality can play in rendering otherwise stable (and seemingly well-performing) growth regimes financially unsustainable. Finally, we demonstrate the important role that consumption em-

\footnotetext{
${ }^{2}$ See also Foster and Magdoff (2009), Kumhof and Rancière (2010) and Setterfield (2013).
} 
ulation ("keeping up with the Joneses") plays in making a growth regime unsustainable, by showing that it matters exactly who poorer households emulate (rather than simply whether or not emulation effects are present).

The remainder of the paper is organized as follows. In the next section, we describe the accounting relationships between households, firms, and banks that make our model stock-flow consistent. The third section describes the behavior of firms and households, with a particular focus on the consumption, borrowing, and debt-servicing decisions of the latter. In the fourth section we discuss the comparative static properties of our model, while the fifth section focuses on the models' debt dynamics and the implied (un)sustainability of growth regimes that differ with respect to the distribution of income. The sixth section offers some conclusions, chief among which is that over the last three decades, distributional changes between the Golden Age (1948-73) and Neoliberal (1980-2007) growth regimes in the presence of consumption emulation effects can be strongly associated with rendering the growth dynamics of advanced capitalist economies financially unsustainable.

\section{Accounting}

Table 1: Balance Sheet Matrix

\begin{tabular}{lccccc}
\hline & Workers & Rentiers & Firms & Banks & Sum \\
\hline Capital & & & $K$ & & $K$ \\
Deposits & $D_{W}$ & $D_{R}$ & & $-\left(D_{W}+D_{R}\right)$ & 0 \\
Loans & $-D$ & & & $D$ & 0 \\
Equity & & $E$ & $-E$ & & 0 \\
Net worth & $D_{W}-D$ & $D_{R}+E$ & $K-E$ & $D-\left(D_{W}+D_{R}\right)$ & $K$ \\
\hline
\end{tabular}

It is useful to begin by setting out some accounting relationships that show how the heterogeneous households whose behavior we model in the following sections are related to one another, and to the rest of the economy. We begin by writing:

$$
Y=W_{p} N+W_{r} \alpha N+\Pi
$$


Table 2: Transaction Flow Matrix

\begin{tabular}{|c|c|c|c|c|c|c|c|}
\hline & \multirow[b]{2}{*}{ Workers } & \multirow[b]{2}{*}{ Rentiers } & \multicolumn{2}{|c|}{ Firms } & \multicolumn{2}{|c|}{ Banks } & \multirow[b]{2}{*}{ Sum } \\
\hline & & & Current & Capital & Current & Capital & \\
\hline Consumption by wage & $-C_{W}$ & $-C_{R}$ & $C_{W}+C_{R}$ & & & & 0 \\
\hline Consumption by debt & $-\dot{D}$ & & $\dot{D}$ & & & & 0 \\
\hline Investment & & & $I$ & $-I$ & & & 0 \\
\hline Wages & $W_{p} N$ & $W_{r} \alpha N$ & $-W$ & & & & 0 \\
\hline Firms' profits & & $\Pi$ & $-\Pi$ & & & & 0 \\
\hline Deposit interest & $i D_{W}$ & $i D_{R}$ & & & $-i\left(D_{W}+D_{R}\right)$ & & 0 \\
\hline Loan interest & $-i D$ & & & & $i D$ & & 0 \\
\hline Deposit flows & $-\dot{D_{W}}$ & $-\dot{D_{R}}$ & & & & $\left(\dot{D_{W}}+\dot{D_{R}}\right)$ & 0 \\
\hline Loan flows & $\dot{D}$ & & & & & $-\dot{D}$ & 0 \\
\hline Issues of equities & & $-\dot{E}$ & & $\dot{E}$ & & & 0 \\
\hline Sum & 0 & 0 & 0 & 0 & 0 & 0 & 0 \\
\hline
\end{tabular}

where $Y$ denotes real income, $\Pi$ denotes total real profits, $W_{p}$ is the real wage of production workers, $W_{r}$ is the real wage of supervisory workers, $N$ is the number of workers employed, and $\alpha<1$ denotes the ratio of production workers to managers, given by technology and the organizational structure of the production process.

In this formulation, we treat $W_{p} N$ as the income of working households and $W_{r} \alpha N+\Pi$ as the income of rentier households (capitalists and supervisory workers). In other words, the three types of income recipients (production and non-supervisory workers, supervisory workers, and capitalists) define two types of households (working and rentier households). ${ }^{3}$ Our motivation for this bilateral distinction comes from the claim of Palley (2013b) that there is a marked distinction (in terms of income and wealth shares) between the bottom 80 per cent and the top 20 per cent of the US income distribution, with the bottom 80 per cent corresponding to the working class, ${ }^{4}$ and the top 20 per cent corresponding to the middle class (including the upper middle class of capitalists and the "working rich" who make up the top one per cent of the income distribution). ${ }^{5}$ As will become clear in the next section,

\footnotetext{
${ }^{3}$ As explained by Palley (2012, p.462), this is equivalent to assuming that capitalists receive some part of the wage bill as remuneration for their role as managers.

${ }^{4}$ Production and non-supervisory workers account for 80 per cent of all employees in the US economy.

${ }^{5}$ The "working rich" refers to upper-level salaried employees who have, in increasing numbers, joined capitalist households at the very top of the income distribution over the last thirty years. See Piketty and Saez (2003), Wolff and Zacharias (2009) and Atkinson et al. (2011) on the evolution of "top incomes" in the US. See also Mohun (2006) on the correct accounting treatment of the "wage" income earned by the "working rich".
} 
our ultimate purpose in making this bilateral distinction between households is that we can impute to each identifiably different characteristics when it comes to consumption behavior. First, we assume that working households conventionally consume a larger fraction of their current income than do rentier households. Second, we assume that working households borrow to finance some part of their current consumption, whereas rentier households do not.

Bearing in mind the second of the two assumptions stated above, the balance sheet and transaction flow relationships between working and rentier households and the rest of the domestic economy are described in the social accounting matrices (SAMs) in Tables 1 and 2. The SAMs in Tables 1 and 2 serve to illustrate both how working and rentier households are related to each other, and how the household sector and corporate sector of the economy fit together. There are several noteworthy features of these SAMs. First, observe that because our purpose in this paper is to model aggregate consumption spending, our behavioral analysis inevitably focuses on households. The image of firms and banks that emerges from the SAMs in Tables 1 and 2 is highly stylized and simplified. Firms do not borrow to finance investment expenditure, which is instead funded solely by capitalists who purchase equities. ${ }^{6}$ Banks, meanwhile, are no more than passive intermediaries between households, earning no income from the intermediation services they provide and accumulating no net worth.

Note also that the deposits of rentier households fund only part of the debt accumulated by working households for the purpose of consumption expenditure. Part of the debt accumulated by working households is funded by other working households, as a result of the fact that working households are assumed to engage in some amount of saving out of their current income. In other words, working households are assumed to engage in saving out of current income even as they accumulate debt to finance current consumption. ${ }^{7}$ This

\footnotetext{
${ }^{6}$ For simplicity, the price of equity is fixed and normalized to one.

${ }^{7}$ As is clear from Tables 1 and 2, saving by working households results in the latter accumulating wealth exclusively in the form of interest-earning bank deposits: all corporate equity is owned by rentier households. This is a departure from the approach taken by Pasinetti (1962) and Palley (2012), in which physical capital is the only asset that households can own, as a result of which workers receive some share of profit income. Clearly, the two approaches need not be mutually exclusive.
} 
behavior is consistent with stylized facts, and may be explained as follows. First, working households are, themselves, heterogeneous: some engage in saving and do not debt-finance current consumption, while others do not save and simultaneously consume more than they earn by borrowing. Second, in an environment of fundamental uncertainty and imperfect credit markets, it is rational for any individual household that wishes to consume in excess of current income to simultaneously save and borrow. This is because uncertainty implies a precautionary demand for liquidity to meet unforeseen contingencies, while imperfect credit markets mean that dis-saving and borrowing are not perfect substitutes: a household is always legally entitled to draw down its previously accumulated wealth, but has no similar entitlement to borrow.

\section{Behavior}

\subsection{Production and Firms}

Production in the economy is described by the following fixed coefficient production function:

$$
Y=\min \{\kappa K, \varepsilon \operatorname{Min}[N, M / \alpha]\}
$$

where $Y$ denotes real output and $M$ denotes the number of managers. ${ }^{8}$ The fixed real wage earned by workers is assumed to be a fraction of the real wage of managers, or: ${ }^{9}$

$$
W_{r}=\phi W_{p}
$$

\footnotetext{
${ }^{8}$ A similar specification is adopted in Palley (2013a).

${ }^{9}$ The same relationship holds in terms of the nominal wage since our model excludes inflation.
} 
where $\phi>1$. Total real wage income is then:

$$
\begin{array}{r}
W=W_{p} N+W_{r} M \\
\Rightarrow W=W_{p} N+\phi W_{p} \alpha N=(1+\phi \alpha) W_{p} N
\end{array}
$$

If workers' wage share of total income is denoted as $\omega_{p}$ and managers' wage share as $\omega_{r}$, we have the following relationship:

$$
\omega_{r}=\phi \alpha \omega_{p}
$$

Firms are characterized by their investment demand and markup pricing behavior. We treat the pricing behavior of firms in standard neo-Kaleckian fashion: price is a markup over unit labor costs, reflecting an oligopolistic market structure (Harris, 1974; Asimakopulos, 1975). Such markup pricing behavior implies a standard expression for the gross profit share $(\pi=\Pi / Y):$

$$
\pi=\frac{\tau}{1+\tau}
$$

where $\tau$ is the (fixed) mark up applied to unit labor costs to determine prices.

Let $r=\Pi / K$ denote the profit rate. Following Stockhammer (1999), our desired investment rate $\left(g_{K}=I / K\right)$ responds positively to the profit rate.

$$
g_{K}=\kappa_{0}+\kappa_{r} r
$$

The parameters in this investment function are positive: $\kappa_{0}$ captures the state of business confidence; ${ }^{10}$ and $\kappa_{r}$ captures the sensitivity of desired investment to the profit rate. The current profit rate approximates the expected rate of return, and hence induces investment demand (Blecker, 2002; Stockhammer, 1999).

Note that the profit rate and hence the accumulation rate can be expressed in terms of the capacity utilization rate $(u=Y / K)$. The gross profit rate is just the product of the

\footnotetext{
${ }^{10}$ This term is often referred to as animal spirits.
} 
gross profit share and the capacity utilization rate:

$$
r=\pi u
$$

Substitution into equation (7) then allows us to express the rate of accumulation in terms of the capacity utilization rate:

$$
g_{K}=\kappa_{0}+\kappa_{r} \pi u
$$

\subsection{Consumption}

On the basis of the SAM in Table 2, aggregate consumption $(C)$ can be written as:

$$
C=C_{W}+C_{R}+\dot{D}
$$

Note that borrowing by working households to finance consumption spending independently

of current income, $\dot{D}$, results in the accumulation of a stock of debt by these households and the accumulation of an equivalent stock of financial assets by other households. The influence of debt on consumption will become clear below when we explicitly model $C_{W}$ and $C_{R}$. The influence of financial assets (and, indeed, wealth more generally) on consumption spending is, however, overlooked in what follows for the sake of simplicity. Stylized facts (an extremely unequal distribution of wealth - and particularly financial assets - coupled with small marginal propensities to spend on the part of the richest members of society) suggest that the impact of wealth on aggregate consumption is modest. ${ }^{11}$

We next model borrowing by working households as:

$$
\dot{D}=\beta\left(C^{T}-C_{W}\right), \beta>0
$$

\footnotetext{
${ }^{11}$ For empirical evidence supporting these claims, see Wolff (2010) and Onaran et al. (2011).
} 
where $C^{T}$ denotes a target level of consumption. The exact size of the adjustment parameter $\beta$ is sensitive to (inter alia) household borrowing norms and financial market lending norms. Unlike Dutt (2005, 2006), we do not explicitly model a constraint on workers' borrowing arising from the preferences of lenders with respect to workers' indebtedness. But as should be clear form the definition of $\beta$, borrowing by workers is neverthless constrained by rentier behavior. Hence rentier concerns about the credit worthiness of working households, for example, will lower the value of $\beta$ and reduce workers' borrowing, ceteris paribus. Note also that in equation (11), borrowing only partially closes the gap between $C^{T}$ and $C_{W}$ at any point in time. This means that that working households typically consume at a level that differs from the level of consumption to which they aspire. ${ }^{12}$

Implicit in equations (10) and (11) is the notion that working households engage in a three-step decision making process when determining their current consumption spending. First, they identify a target level of consumption, $C^{T}$. Second, they decide what part of current income to devote to consumption spending, $C_{W}$. Finally, and in accordance with equation (11), they determine what to borrow. Substituting (11) into (10), we arrive at:

$$
C=(1-\beta) C_{W}+\beta C^{T}+C_{R}
$$

It follows from equation (12) that aggregate consumption is increasing in $C_{W}, C_{R}$, and $C^{T}$.

The consumption target $C^{T}$ captures the level of consumption to which working households aspire in any given period and is specified as:

$$
C^{T}=\eta C_{R}
$$

$C_{R}$ is the level of consumption of a contemporaneous reference group (in this model, rentier

\footnotetext{
${ }^{12}$ Note that with $C^{T}>C_{W}, \dot{D} \gg 0$ in equation (11). In other words, the indebtedness of working households is strictly increasing over time. Although the model does not provide for deleveraging by working households unless $C^{T}<C_{W}$, it does not altogether ignore repayments of principal in the course of debt servicing. Hence $\dot{D}>0$ can be thought of as net new borrowing, with total borrowing exceeding repayments of principal for working households as a whole whenever $C^{T}>C_{W}$.
} 
households). Workers observe the consumption patterns of rentier households and seek to emulate rentier consumption. The larger is the emulation parameter $\eta$, the higher the target level of consumption and hence the more debt financed consumption is undertaken by workers, as shown in equation (11). The consumption function we are modeling here can be thought of as sharing an affinity with the relative income hypothesis associated with Duesenberry (1949).

Following Kim et al. (Forthcoming), we assume that households, in order to service the debts that accrue as a result of their consumption behavior, pursue an ordered method of coping with increased financial obligations. The motivation for this assumption comes from two sources. The first is the argument that debt servicing expenditures by households are better thought of as a monetary outlay undertaken volitionally by households, rather than an autonomous deduction from gross household income (Cynamon and Fazzari, 2012). The seond is the observations of Lusardi et al. (2011) who, based on their analysis of data from the 2009 TNS Global Economic Crisis Survey of households in 13 countries, suggest that "just as corporations tend to fund themselves first by drawing upon internal funds, households address financial shocks first by drawing down savings" (Lusardi et al., 2011, p.27). ${ }^{13}$

To allow for this "pecking order" theory of how households cope with increasing financial demands, we consider a behavior in which workers are assumed to consume a conventional fraction of their gross wage income, and then use the residual to fund either debt servicing or current saving as the demands of the former allow. In this scenario, then, working households regard saving as a luxury that is foregone first (before consumption out of current income is affected) in the event that they confront higher debt servicing obligations. ${ }^{14}$ In this case,

\footnotetext{
${ }^{13}$ Lusardi et al. (2011) study the ways in which households come up with emergency funds of 2000 dollars in 30 days in the event of a financial shock, finding that savings is the primary source of emergency funds for a large proportion of households. Their study does not provide direct evidence that households sacrifice savings to preserve their consumption expenditures following a financial shock. However, their results do suggest the possibility that, in the event of a financial shock, households are willing to sacrifice savings while attempting to maintain their consumption expenditures.

${ }^{14}$ The notion that working households treat saving as a luxury and otherwise live "hand to mouth," using current income in the first instance to fund current consumption and debt servicing obligations, dovetails with a second empirical observation made by Lusardi et al. (2011) - that approximately 25 percent of Americans self-report that they certainly could not come up with 2,000 dollars in 30 days, while a further 19 percent
} 
the consumption functions of workers and rentiers are:

$$
\begin{gathered}
C_{W}=c_{W} W_{p} N \\
C_{R}=c_{\pi}\left[W_{r} \alpha N+\Pi+i\left(D-D_{W}\right)\right]
\end{gathered}
$$

It follows from the description of consumption behavior above that total saving by working households is:

$$
S_{W}=\left(1-c_{W}\right) W_{p} N-i D_{R}
$$

Note that it also follows from equations (15) and (16) that total saving in the economy can be written as:

$$
S=S_{W}+S_{R}=\left[\left(1-c_{W}\right)+\left(1-c_{\pi}\right) \phi \alpha\right] W_{p} N+\left(1-c_{\pi}\right) \Pi-c_{\pi} i D_{R}
$$

from which it is evident that $\partial S / \partial D_{R}=-i c_{\pi}<0$. In other words, aggregate saving and hence, for any given level of income, the average propensity to save of households - is decreasing in the indebtedness of net debtor households. This result mirrors the coincidence of falling household saving rates and rising household indebtedness actually observed in the US economy over the last three decades (see, for example, Palley (2002); Barba and Pivetti $(2009))$.

\section{Temporary Equilibrium}

Commodity market equilibrium in the model has a standard representation:

$$
Y=C_{W}+C_{R}+\dot{D}+I
$$

claim that they could only do so by pawning or selling possessions or taking payday loans. 
Substituting equations (11), (14), and (15) into this equilibrium condition, we can derive the following expression for goods market equilibrium:

$$
Y=c_{W}(1-\beta) W_{p} N+c_{\pi}(1+\beta \eta)\left[\phi \alpha W_{p} N+\Pi+i\left(D-D_{W}\right)\right]+I
$$

Normalizing all variables by the capital stock and utilizing equation (9) allows us to express commodity market equilibrium in terms of the rate of capacity utilization: ${ }^{15}$

$$
u=c_{w}(1-\beta) \omega_{p} u+c_{\pi}(1+\beta \eta)\left(\phi \alpha \omega_{p} u+\pi u+i d_{R}\right)+\kappa_{0}+\kappa_{r} \pi u
$$

We can then derive the following reduced-form expressions for the capacity utilization, profit, and accumulation rates:

$$
\begin{gathered}
u=\frac{(1+\alpha \phi)\left[\kappa_{0}+i d_{R} c_{\pi}(1+\beta \eta)\right]}{\left\{(1+\alpha \phi)\left[1-\pi\left[\kappa_{r}+c_{\pi}(1+\beta \eta)\right]\right]-(1-\pi)\left[c_{W}(1-\beta)+c_{\pi} \alpha(1+\beta \eta) \phi\right]\right\}} \\
r=\frac{\pi(1+\alpha \phi)\left[\kappa_{0}+i d_{R} c_{\pi}(1+\beta \eta)\right]}{\left\{(1+\alpha \phi)\left[1-\pi\left[\kappa_{r}+c_{\pi}(1+\beta \eta)\right]\right]-(1-\pi)\left[c_{W}(1-\beta)+c_{\pi} \alpha(1+\beta \eta) \phi\right]\right\}} \\
g_{K}=\kappa_{0}+\frac{\kappa_{r} \pi(1+\alpha \phi)\left[\kappa_{0}+i d_{R} c_{\pi}(1+\beta \eta)\right]}{\left\{(1+\alpha \phi)\left[1-\pi\left[\kappa_{r}+c_{\pi}(1+\beta \eta)\right]\right]-(1-\pi)\left[c_{W}(1-\beta)+c_{\pi} \alpha(1+\beta \eta) \phi\right]\right\}}
\end{gathered}
$$

Note that it follows from equations (1) and (5) that:

$$
\begin{array}{r}
1-\pi=(1+\phi \alpha) \omega_{p} \\
\Rightarrow \omega_{p}=\frac{1-\pi}{1+\phi \alpha}
\end{array}
$$

On the basis of this result, $\omega_{p}$ has been replaced with $(1-\pi) /(1+\alpha \phi)$ in the expressions for $u, r$, and $g_{K}$ derived above.

\footnotetext{
${ }^{15}$ The term $d_{R}$ in equation (20) is workers' net debt (owed to rentier households) to capital stock ratio. Note that this bears a straightforward relationship to the more intuitive debt to income ratio, which is given by $D_{R} / W_{p} N=d_{R} / \omega_{p} u$.
} 


\subsection{Comparative statics and discussion}

Table 3: Short-Run Comparative St
\begin{tabular}{rllllll} 
& $\kappa_{0}$ & $\pi$ & $i$ & $d_{R}$ & $\eta$ \\
\hline$u$ & + & $?$ & + & + & + \\
$r$ & + & $?$ & + & + & + \\
$g_{K}$ & + & $?$ & + & + & + \\
\hline Positive & $d_{R}$ is assumed.
\end{tabular}

The comparative static results for $u, r$ and $g_{K}$ derived from the temporary equilibria in equations $(21)-(23)$ are reported in Table 3. They reveal several interesting features of the growth regime when household behavior conforms to the "pecking order" theory of debt servicing discussed in the previous section. In view of the fact that the responses of $u, r$ and $g_{K}$ with respect to small variations in $\kappa_{0}, \pi, i, d_{R}$, and $\eta$ are always of the same sign, the discussion that follows focuses exclusively on comparative statics involving the equilibrium growth rate, $g_{K}$.

Given the focus of our analysis (and for reasons that will become apparent below), it is useful to begin by examining the comparative static results reported in Table 3 that pertain to borrowing and debt servicing by working households. First, and as expected, we observe $\partial g_{K} / \partial \eta>0$. Since $\eta$ captures the propensity of working households to emulate the consumption standards of rentiers in equation (13), and since (given $\beta>0$ ) this emulation effect drives borrowing by working households in (11), the result that $\partial g_{K} / \partial \eta>0$ simply amounts to the suggestion that increased borrowing fuels demand formation and hence growth.

Of course, borrowing also results in debt accumulation and the servicing of debts sets up a flow of transfer payments from debtors to creditors that (ceteris paribus) is conventionally thought to create a deflationary drag in demand-led growth models. ${ }^{16}$ This is because of the higher marginal propensity to consume of debtor households. It is therefore interesting to note that contrary to this conventional wisdom, Table 3 draws attention to a seemingly

\footnotetext{
${ }^{16}$ See, for example, Dutt $(2005,2006)$ and Hein $(2012$, chpt.5).
} 
perverse redistributive result: $\partial g_{K} / \partial i, \partial g_{K} / \partial d_{R}>0$, indicating that increased debt servicing (which transfers income from high marginal propensity to consume working households to low marginal propensity to consume rentier households) boosts growth. Note that as a consequence of this, the economy is effectively "super charged" by working household's debt accumulation, because both borrowing $\left(\partial g_{K} / \partial \eta>0\right)$ and the subsequent servicing of accumulated debt by working households contribute positively to macroeconomic performance.

The intuition for this seemingly perverse redistributive result is straightforward. ${ }^{17} \mathrm{Be}-$ cause of working households' "pecking order" approach to debt servicing commitments, the transfer of income towards rentiers associated with debt servicing involves a transfer of income not spent by working households towards rentier households, who then apply a positive marginal propensity to consume to additional income regardless of its source. In short, part of the income transferred towards rentiers - all of which would otherwise constitute a leakage from the circular flow of income - is transformed into an injection, because $c_{\pi}>0$. This stimulates growth in a demand-led economy, ceteris paribus. The comparative static results in the third and fourth columns of Table 3 thus illustrate the importance of the precise way that households are characterized as meeting their debt servicing obligations, as originally emphasized by Kim et al. (Forthcoming).

The observations made above about the effects of borrowing and debt servicing on growth now bring us to the comparative static results in the second column of Table 3, where the ambiguous sign of $\partial g_{K} / \partial \pi$ reveals that the growth regime can be either wage- or profit-led. First note that given the form of the investment function in equation (7):

$$
\frac{\partial g_{K}}{\partial \pi}=\frac{\partial g_{k}}{\partial \pi}+\frac{\partial g_{k}}{\partial u} \frac{\partial u}{\partial \pi}=\kappa_{r} u+\kappa_{r} \pi \frac{\partial u}{\partial \pi}
$$

Since $\kappa_{r} u, \kappa_{r} \pi \gg 0$, the sign of this derivative clearly depends on the sign of $\partial u / \partial \pi$. Using equation (21) it is possible to show that:

\footnotetext{
${ }^{17}$ See also Kim et al. (Forthcoming)
} 


$$
\frac{\partial u}{\partial \pi} \gtreqless 0 \Longleftrightarrow \kappa_{r}(1+\alpha \phi)+c_{\pi}(1+\beta \eta)-c_{W}(1-\beta) \gtreqless 0
$$

Observethat if we assume there is no managerial class $(\alpha=0)$ and no net borrowing and hence no net debt accumulation by working households in response to emulation effects $\left(\beta, d_{R}=0\right)$, the behavior of households conforms to that found in a canonical two-class neo-Kaleckian growth model in which workers save some part of their wage income. Under these assumptions, the expression in (26) becomes: ${ }^{18}$

$$
\frac{\partial u}{\partial \pi} \gtreqless 0 \Longleftrightarrow \kappa_{r}+c_{\pi}-c_{W} \gtreqless 0
$$

Comparison of the expressions in (26) and (27) reveals the following. First, the introduction of a managerial class coupled with borrowing and debt accumulation by working households seeking to "keep up with the Joneses" has no qualitative effect on the sign of $\partial g_{K} / \partial \pi$. In both the model with no net borrowing by workers (equation 27) and the extended model (equation 26), the sign of $\partial u / \partial \pi$ and hence $\partial g_{K} / \partial \pi$ is indeterminate: the "paradox of costs" may or may not be observed. Second, the expressions in (26) and (27) reveal that the borrowing and debt accumulation behavior of working households, together with the distinction between production and supervisory labor, has a quantitative effect on the sign of $\partial g_{K} / \partial \pi$. Specifically and ceteris paribus, since $(1+\alpha \phi),(1+\beta \eta)>1$ and $1-\beta<1$ by hypothesis, we are unequivocally more likely to observe $\partial u / \partial \pi>0$ and hence $\partial g_{K} / \partial \pi>0$ (profit-led growth) in our extended model than in the two-class model with no net borrowing by the working class from the capitalist class.

The intuition for this result is straightforward. First, it arises because of the positive impact of emulation-induced borrowing and consumption on growth: redistribution towards profit raises the consumption of the rentier class, which in turn increases the consumption target and borrowing of working households. This can increase the total consumption of

\footnotetext{
${ }^{18}$ This is a linear version of a classical result by Bhaduri and Marglin (1990).
} 
working households even as consumption out of wage income necessarily falls. ${ }^{19}$ Second, the inclusion of a managerial class that purchases equity generates a stronger profitability effect on investment expenditures, as captured by the expression $\kappa_{r}(1+\alpha \phi)$ in equation $(26) .{ }^{20}$ The expressions in (26) and (27) clearly show that the conjunction of these effects is sufficient to ensure that the canonical consumption-expenditure-decreasing effect of a redistribution of income towards profits is modified so that the net effect on expenditures of a rise in the profit share is more likely to be positive.

The critical question that remains is whether or not the growth regime is sustainable in the long run. Sustainability requires that the long run steady state value of $d_{R}$ is compatible with the feasibility condition for debt servicing by working households. Setting equation (16) equal to zero and normalizing by the capital stock, this feasibility condition can be stated as $\left(1-c_{W}\right) \omega_{p} u \geq i d_{R}$. Note that this condition is more restrictive than would be observed in the absence of the "pecking order" approach to debt servicing commitments. Absent the "pecking order" approach, working households would view their entire incomes as being, in the first instance, available for meeting debt servicing commitments, instead of just some fraction $\left(1-c_{W}\right)$ of this income. If the debt servicing feasibility condition stated above is incompatible with the steady state value of $d_{R}$, the growth regime cannot be sustained in the long run and will eventually confront a crisis.

\section{Debt Dynamics}

In this section, we investigate the debt dynamics associated with our model with a view to establishing whether or not growth is financially sustainable. To begin with, note that from

\footnotetext{
${ }^{19}$ It is for this reason that, in the event that the derivative in equation (25) proves to be positive, and in the spirit of Kapeller and Schütz (2012), the resulting growth regime can be labelled consumption-driven, profit-led. As Kapeller and Schütz (2012) note, and as should also be clear from the results derived in this paper, the possibility of such a regime points towards the possible reconciliation of certain stylized facts of the Neoliberal era (redistribution towards profits accompanied by an increase in growth fueled by surging consumption spending and a fall in household saving rates) with the canonical neo-Kaleckian claim that the economy is wage-led - which claim would otherwise appear to be at variance with the stylized facts just noted.

${ }^{20}$ The counterpart of this expression in equation 27 is $\kappa_{r}<\kappa_{r}(1+\alpha \phi)$.
} 
the definition of $d_{R}$, it follows that:

$$
\begin{aligned}
\dot{d_{R}} & =\frac{\beta\left(C^{T}-C_{W}\right)-\dot{D_{W}}}{K}-g_{K} d_{R} \\
& =\beta\left(\eta C_{R} / K-C_{W} / K\right)-\dot{D_{W}} / K-g_{K} d_{R} \\
& =\beta \eta c_{\pi}\left(\omega_{r} u+\pi u+i d_{R}\right)-\left(1+\beta c_{W}-c_{W}\right) \omega_{p} u+i d_{R}-g_{K} d_{R}
\end{aligned}
$$

It is clear from equation (28) that in order to completely express $\dot{d}_{R}$ in terms of the parameters of our model, account needs to be taken of the expressions for $u$ and $g_{K}$ in equations (21) and (23). By setting $\dot{d}_{R}=0$ we can then solve for and identify the stability properties of the steady state value(s) of $d_{R}$. These operations are performed and reported in appendix A.

The analytical results reported in appendix A do not clearly reveal whether or not the two steady state solutions for $d_{R}\left(d_{R 1}\right.$ and $\left.d_{R 2}\right)$ are positive (and therefore economically meaningful), or which of these steady state solutions is stable. It does, however, seem likely that $d_{R 1}>d_{R 2}$, based on observation of the signs of the final term on the RHS of these steady states solutions. ${ }^{21}$ Note, moreover, that, from Table $3, \partial g_{K} / \partial d_{R}>0$. This implies that, in equation (28), the $g_{K} d_{R}$ term is unambiguously increasing in $d_{R}$. Inspection of equation (28) reveals that ceteris paribus, a higher value of $d_{R}$ will therefore generate a stronger stabilizing force, increasing the likelihood that $\partial \dot{d}_{R} / \partial d_{R}<0$. It follows that the higher steady state value, $d_{R 1}$, should correspond to the stable steady state solution of equation (28). Our numerical study in section 5.1 confirms this intuition. Note that the inverse u-shape of the $\dot{d}_{R}$ function implied by this result (and depicted in Figure 1) differs from the conventional u-shaped relationship found in the literature (see, for example, Hein (2012, pp.94-98)). This qualitative difference is further evidence of the importance that attaches to the way that debtor households are conceived as managing their debt-servicing obligations.

We can also consider the proximity of the steady state values of $d_{R}$ to the maximum

\footnotetext{
${ }^{21}$ As will become clear, our numerical solutions reveal that this intuition is correct.
} 
feasible net debt to capital ratio of working households, $d_{R \max }$, and in so doing consider the implications for the sustainability of the growth regime. From the description of working households' consumption and debt servicing behavior provided earlier, it follows that the maximum debt servicing payment that it is possible for workers to sustain is given by:

$$
i D_{R \max }-\left(1-c_{W}\right) W_{p} N=0
$$

It therefore follows that:

$$
\begin{aligned}
d_{\text {Rmax }} & =\left(1-c_{W}\right) \omega_{p} u / i \\
& =\frac{\left(c_{W}-1\right) \kappa_{0} \omega_{p}}{i\left[-1+\kappa_{r} \pi+c_{W} \omega_{p}(1-\beta)+c_{\pi}(1+\beta \eta)\left(\pi+\omega_{p}-c_{W} \omega_{p}+\omega_{p} \alpha \phi\right)\right]}
\end{aligned}
$$

Now consider Figure 1, where $d_{R 1}$ is the stable equilibrium. ${ }^{22}$ If $d_{R \max }=d_{R \max 1}$, then as long as $d_{R} \leq d_{R \max 1}$ initially, the economy will converge to the stable, steady state debt to capital ratio $d_{R 1}$ and the accompanying steady-state growth rate will be sustainable indefinitely (ceteris paribus). If, however, $d_{R \max }=d_{R \max 2}$, then even if $d_{R} \leq d_{R \max 2}$ initially, unless it is also the case that $d_{R}<d_{R 2}$ (in which case the economy will move towards a situation in which working households cease to be net debtors), the stability of $d_{R 1}$ will eventually pull the debt to capital ratio above its maximum sustainable value. The consumption and borrowing behaviors of workers are not sustainable in this case, and the economy will eventually experience a crisis. $^{23}$

\subsection{Numerical Analysis}

In this section, we perform numerical analyses of the dynamics of our model based on empirically plausible parameter values. The baseline parameters for our numerical analysis are

\footnotetext{
${ }^{22}$ In Figure 1, it is assumed for simplicity that both $d_{R 1}$ and $d_{R 2}$ are positive. This need not be the case.

${ }^{23}$ In the context of our model, a "crisis" refers only to a breakdown in the dynamics of the model as specified. Exactly how the economy will react to these circumstances - whether, for example, working households will lower their marginal propensity to consume, or (in cooperation with the financial sector) Ponzi finance still further increases in consumption spending - are topics left to future research.
} 


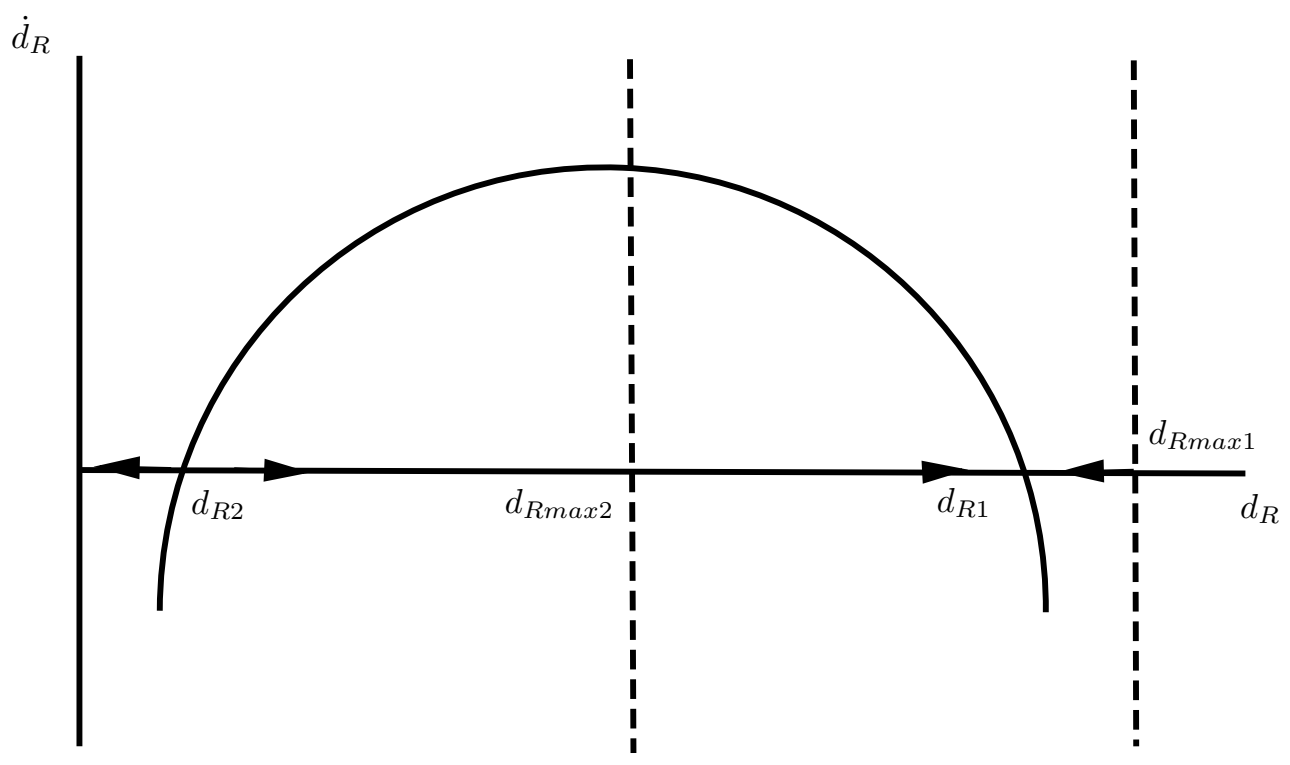

Figure 1: Debt dynamics

presented in Table 4. Note that based on the parameters reported in Table 4, we calculate $\eta$ - the propensity of working households to emulate the consumption of the rentier class as:

$$
\eta=\lambda \delta
$$

where $\lambda$ is Ravina's emulation parameter (see Ravina (2007)), and $\delta$ is a "scaling parameter", set initially as the ratio of consumption by the upper-middle class (capitalists and the working rich) to consumption by the median rentier family (proxied by the ratio of CEO pay to median rentier household income). The presence of $\delta$ in our calculation of $\eta$ allows us to take account of two things. The first is the extent to which the consumption standards of the very affluent affect the aspirations of working households. This influence may be direct, arising as a result of exposure to much-publicised "celebrity lifestyles", or because of the propensity of working households to believe in upward social mobility and the resulting need to consume in accordance with their (expected future) social status (Wisman, 2009, 2013). Alternatively, it may be indirect, resulting from the "expenditure cascades" discussed 
by Levine et al. (2010)). ${ }^{24}$ The second is the growing income inequality within the rentier class in the top quintile of the income distribution. The significance of these factors for our analysis will become apparent in what follows.

Keynesian and radical macroeconomists have distinguished the Golden Age growth regime from the Neoliberal growth regime in the US, the stagflation of the 1970s marking the break between these regimes. One of the main differences between the two regimes is income distribution. From 1943 to the late 1970s, all income classes experienced roughly the same income growth rate of about 3 percent per annum. However, this began to change during the 1970s. For example, between 1973 and 2006, the average annual real income of the bottom 90 percent of households fell while that of the top 1 percent increased 3.2-fold (Palma, 2009, p. 841). As these figures suggest, between 1979 and 2003, income gains for US families have largely been concentrated at the very top of the size distribution of income (Levine et al., 2010).

Table 5 demonstrates the implications for the debt dynamics of our model of variations in the size of three key distributional parameters $\left(\omega_{r}, \omega_{p}\right.$, and $\left.\pi\right)$ between their Neoliberal values (as originally reported in Table 4) and their Golden Age values. ${ }^{25}$ Recall that $\eta=\lambda \delta$, so the variations in $\eta$ in the fourth column of Table 5 can be thought of as a product of a constant propensity to emulate $(\lambda)$ and varying levels of income inequality within the top quintile of the income distribution $(\delta)$ as between the two growth regimes. ${ }^{26}$ With Golden Age distributional parameters, we see that workers become net creditors in the long run, since the stable steady state value $d_{R 1}$ is negative. With the Neoliberal distributional parameters, however, workers become net debtors in the long run $\left(d_{R 1}=1.327\right)$.

\footnotetext{
${ }^{24}$ Bertrand and Morse (2013) provide empirical evidence of this phenomenon, which they term "trickle down consumption". The authors find that middle income US households would have saved 2.6-3.2 per cent more by the mid-2000s had top incomes (defined as incomes in either the top quintile or top decile of the income distribution) grown at the same rate as median household income. Consistent with an emulationbased explanation of this outcome, they also find that it is middle income families' expenditure on the most income elastic and visible goods and services that is particularly responsive to top income growth.

${ }^{25}$ The latter appear in the first three columns of the second row of Table 5, and are calculated from the same sources reported in Table 4. Note also that the values of $\omega_{r}$ reported in Table 5 are calculated from the values of $\omega_{p}, \alpha$ and $\phi$, given that $\omega_{r}=(1+\alpha \phi) \omega_{p}$.

${ }^{26}$ The value of $\delta$ for the Golden Age is calculated from the same source reported in Table 4.
} 
Table 4: Parameter values

Parameter Value Source

\begin{tabular}{|c|c|c|}
\hline$c_{W}$ & 0.94 & $\begin{array}{c}\text { Authors' calculations based on } \\
\text { Bunting (1998) }\end{array}$ \\
\hline$c_{\pi}$ & 0.20 & Setterfield and Budd (2011) \\
\hline$\beta$ & 0.10 & Authors' calculations ${ }^{1}$ \\
\hline$\lambda$ & 0.29 & Ravina $(2007)$ \\
\hline$\delta$ & 74.89 & $\begin{array}{l}\text { Authors' calculations based on } \\
\text { Mishel and Sabadish (2012) and } \phi\end{array}$ \\
\hline$\phi$ & 2.27 & $\begin{array}{c}\text { Authors' calculations based on } \\
\text { Mishel et al. (2007) }\end{array}$ \\
\hline$\alpha$ & 0.25 & Authors' calculations ${ }^{2}$ \\
\hline$\omega_{p}$ & 0.42 & $\begin{array}{c}\text { Authors' calculations based on } \\
\text { Mohun (2006), Figure } 7\end{array}$ \\
\hline$\pi$ & 0.34 & Authors' calculations ${ }^{3}$ \\
\hline$\kappa_{0}$ & 0.045 & Authors' calculations ${ }^{4}$ \\
\hline$\kappa_{r}$ & 0.5 & $\begin{array}{l}\text { Lavoie and Godley (2001-02), } \\
\text { Skott and Ryoo (2008) }\end{array}$ \\
\hline$i$ & 0.0481 & $\begin{array}{c}\text { Authors' calculations based on } \\
\text { World Bank Data }\end{array}$ \\
\hline
\end{tabular}

1. Set in accordance with other parameters to satisfy the Keynesian stability condition.

2. Based on production workers accounting for 80 per cent of total employment. See (Mishel et al., 2007, p.118).

3. Set in accordance with $\pi=1-(1+\alpha \phi) \omega_{p}$.

4. Set in accordance with other parameters to yield capacity utilization rate of approximately 80 per cent.

5. See data.worldbank.org.

Table 5: Change in Distribution: Golden Age and Neoliberal Regimes

\begin{tabular}{lccccccc}
\hline$\omega_{r}$ & $\omega_{p}$ & $\pi$ & $\eta$ & $d_{R 1}$ & $d_{R 2}$ & $d_{R} \max$ & $c$ \\
\hline 0.23835 & 0.42 & 0.34165 & 21.72 & 1.327 & -1.218 & 0.262 & -0.043 \\
0.2304 & 0.48 & 0.2896 & 2.92 & -0.446 & -2.442 & 0.088 & 0.025 \\
\hline
\end{tabular}


The eighth column of Table 5 reports the feasibility coefficient $(c)$ for debt servicing by working households at the stable steady state $d_{R 1}$ :

$$
c=\left(1-c_{W}\right) \omega_{p} u-i d_{R 1}
$$

If the feasibility coefficient is negative, then $d_{R \max }$ is below the stable steady state, and the growth regime cannot be sustained since workers cannot continue to meet their debt service commitments (see, for example, $d_{R \max 2}$ in Figure 1). Although $d_{R \max }$ is higher under the Neoliberal regime than during the Golden Age (see Table 5, column 7), the feasibility coefficient is negative, indicating that $d_{R \max }$ is below the stable steady state $d_{R 1}$. Workers cannot afford to meet their debt service commitments in the long run, and hence the regime is unsustainable. Under the Golden Age regime, however, we see that the value of $c$ is positive, indicating that $d_{R \max }$ is above the stable steady state $d_{R 1}$ (see, for example, $d_{R \max 1}$ in Figure 1). The Golden Age regime is therefore sustainable. The results in Table 5 therefore show that changes in income distribution and corresponding (induced) changes in emulation behavior are crucial to our understanding of the long run sustainability of different growth regimes. Interpreted literally, our results suggest that in the model developed in this paper, distributional changes (and accompanying induced emulation effects) on a scale similar to those actually observed in the transition from the Golden Age to the Neoliberal growth regime suffice to render the growth process unsustainable, holding all other structural features of the Neoliberal regime (as reflected in the parameters reported in Table 4) constant. In short, although redistribution of income away from production workers induces higher consumption expenditures by workers (through emulation and borrowing) and rentiers (through an increase in their interest income) and hence a higher rate of growth (in accordance with the notion of Kapeller and Schütz (2012) that Neoliberalism is a consumption-driven profit-led regime), workers' debt accumulation eventually becomes unsustainable. Workers' consumption and borrowing behaviors must change if the growth 
regime established by income redistribution away from production workers is to avoid encountering a crisis.

Table 6: Emulation Effect

\begin{tabular}{lcccc}
\hline$\eta$ & $d_{R 1}$ & $d_{R 2}$ & $d_{R} \max$ & $c$ \\
\hline 0.29 & -0.434 & -3.763 & 0.068 & 0.024 \\
2.92 & -0.246 & -2.653 & 0.074 & 0.015 \\
10 & 0.452 & -1.555 & 0.102 & -0.016 \\
21.72 & 1.327 & -1.218 & 0.262 & -0.044 \\
\hline The Neoliberal distribution parameter val- \\
ues are used for the result in the table. The \\
Golden Age distribution parameters generate \\
qualitatively the same result.
\end{tabular}

It is important to understand that changes in distribution between working and rentier households are not, per se, sufficient to generate an unsustainable growth regime. There must also be an accompanying change in consumption emulation behavior. The cultural components of consumption behavior emphasized by Schor (1998), Cynamon and Fazzari (2008, 2013), and Wisman $(2009,2013)$ are therefore an important factor in generating unsustainable growth dynamics. Table 6 shows how the financial dynamics of our model react to different assumptions about the emulation parameter, $\eta$, based on variations in the scaling paraemter $\delta$ within the range $1 \leq \delta \leq 74.89$. At the lower extreme of this range $(\delta=1)$, working households emulate the median rentier household. At the upper extreme $(\delta=74.89)$, workers' consumption aspirations are influenced by the upper-middle class (capitalists and the working rich). The variation in $\delta$ between these extremes contemplated in Table 6 allows us to analyze (ceteris paribus) the effects of variations in $\delta$ (capturing the attractiveness of celebrity lifestyles and/or the strength of expenditure cascades) - and hence who working households seek to emulate - on the financial sustainability of a growth regime.

As is clear from Table 6 , as the value of $\eta$ increases, the steady state values $d_{R 1}$ and $d_{R 2}$ increase as well. As a higher $\eta$ generates a higher capacity utilization rate, $d_{R m a x}$ also increases in size. A higher emulation parameter also generates faster economic growth (as shown in Table 3). However, the calculated values of the feasibility coefficient $c$ in Table 
6 show that, with ever higher values of $\eta$ and ceteris paribus, the feasibility coefficient eventually becomes negative and the resulting growth regime cannot be sustained in the long run. Recall that, given the propensity to emulate, $\lambda$, the size of $\eta$ is related to the distributional parameter $\delta{ }^{27}$ What this suggests is that in addition to the redistribution of income between working and rentier households, the redistribution of income within the top quintile of the income distribution towards the very affluent coupled with the propensity of working households to emulate the consumption standards of the very affluent (either directly or through expenditure cascades) is what drives the transition from a sustainable to an unsustainable growth regime. This, in turn, suggests that in addition to the importance for the properties of a growth regime that attaches to working households' debt servicing behavior, importance also attaches to exactly who working households seek to emulate in the process of "keeping up with the Joneses", rather than simply whether or not such emulation effects exist. If either exposure (through the media) to "celebrity lifestyles" or expenditure cascades are sufficiently strong, the results in this paper suggest that the consequences for the sustainability of a growth regime characterized by any given distribution of income between working and middle class households are potentially adverse.

\section{Conclusion}

In this paper, we augment a conventional neo-Kaleckian model of growth and distribution with a model of the household sector in which working households, motivated by a desire to emulate the consumption standards of rentier households, borrow in order to finance some part of their total consumption expenditures. The comparative static properties and debtdynamics of the model are then studied - the latter in an effort to identify whether or not growth is financially sustainable.

Our model yields three key results. First - and in tandem with the the findings of Kim et al. (Forthcoming) - it demonstrates the important effect on the characteristics of a

\footnotetext{
${ }^{27}$ From equation (31), $\eta=\lambda \delta$.
} 
growth regime of exactly how working households manage their debt servicing obligations. Second, it illustrates the potential significance of income redistribution away from working households for rendering an otherwise stable (and seemingly well-performing) growth regime financially unsustainable. Finally, it reveals that exactly who working households seek to emulate when formulating their consumption aspirations has an important effect on whether or not a growth regime is financially sustainable. This last result draws attention to the importance of growing inequality within the upper echelons of the income distribution (as well as inequality between the upper echelons and the rest of the income distribution) for the financial (un)sustainability of the growth process. It is hoped that these results will contribute to our understanding of the origins of the Great Recession, and what is required to restore robust (i.e., both sufficiently rapid and sustainable) economic growth. 


\section{References}

Asimakopulos, Athanasios (1975, August). "A Kaleckian theory of income distribution." Canadian Journal of Economics 8(3), 313-333.

Asimakopulos, Athanasios (1983, September-December). "Kalecki and Keynes on finance, investment and saving." Cambridge Journal of Economics 7(3-4), 221-233.

Atkinson, Anthony B., Thomas Piketty, and Emmanuel Saez (2011). "Top incomes in the long run of history." Journal of Economic Literature 49, 3-71.

Barba, Aldo and Massimo Pivetti (2009). "Rising household debt: Its causes and macroeconomic implications - a long-period analysis." Cambridge Journal of Economics 33(1), $113-137$.

Bertrand, Marianne and Adair Morse (2013). "Trickle down consumption." NBER Working Paper 18883.

Bhaduri, Amit and Stephen A. Marglin (1990). "Unemployment and the real wage: The economic basis for contesting political ideologies." Cambridge Journal of Economics 14(4), 375-393.

Blecker, Robert (2002). "Distribution, demand, and growth in neo-Kaleckian macro models." In Mark Setterfield, ed., The Economics of Demand-Led Growth: Challenging the Supply-Side Vision of the Long Run, pp. 129-152. Cheltenham: Edward Elgar.

Bunting, David (1998). "Distributional basis of aggregate consumption." Journal of Post Keynesian Economics 20(3), 389-413.

Cynamon, Barry Z. and Steven M. Fazzari (2008). "Household debt in the consumer age: Source of growth-risk of collapse." Capitalism and Society 3(2), Article 3.

Cynamon, Barry Z. and Steven M. Fazzari (2012). "Measuring household demand: a cash flow measure." Washington University in St Louis, mimeo. 
Cynamon, Barry Z. and Steve M. Fazzari (2013). "The end of the consumer age." In Steve M. Fazzari Cynamon, Barry Z. and Mark Setterfield, eds., After the Great Recession: The Struggle for Economic Recovery and Growth, pp. 129-157. Cambridge University Press.

Duesenberry, J. S (1949). Income, Saving and the Theory of Consumer Behaviors. Cambridge, MA: Harvard University Press.

Dutt, Amitava K. (2005). "Consumption, debt and growth." In Mark Setterfield, ed., Interactions in Analytical Political Economy, pp. 155-78. Armonk, NY: M.E. Sharpe.

Dutt, Amitava K. (2006). "Maturity, stagnation and debt: a Steindlian approach." Metroeconomica 57, 339-364.

Dutt, Amitava K. (2008). "The dependence effect, consumption and happiness: Galbraith revisited." Review of Political Economy 20(4), 527-550.

Foster, John Bellamy and Fred Magdoff (2009). The Great Financial Crisis. New York, New York: Monthly Review Press.

Harris, Donald J. (1974). "The price policy of firms: The level of employment and distribution of income in the short run." Australian Economic Papers 13, 144-151.

Hein, Eckhard (2012). The Macroeconomics of Finance-dominated Capitalism - and its Crisis. Cheltenham, UK: Edward Elgar.

Kapeller, Jakob and Bernhard Schütz (2012). "Conspicuous consumption, inequality and debt: the nature of consumption-driven profit-led regimes." Johannes Kepler University of Linz Working Paper No. 1213.

Kim, Yun K (2012). "Emulation and consumer debt: Implications of keeping-up with the jones." Working Paper 1208, Trinity College Working Paper Series. 
Kim, Yun K, Mark Setterfield, and Yuan Mei (Forthcoming). "A theory of aggregate consumption." European Journal of Economics and Economic Policies: Intervention.

Kumhof, Michael and Romain Rancière (2010). "Inequality, leverage and crises." Working Paper 268, International Monetary Fund.

Lavoie, Marc and Wynne Godley (2001-02). "Kaleckian models of growth in a coherent stock-flow monetary framework." Journal of Post Keynesian Economics 24(2), 277311.

Levine, Adam Seth, Robert H. Frank, and Oege Dijk (2010). "Expenditure cascades." http://ssrn.com/abstract=1690612.

Lusardi, A., D.J. Schneider, and P. Tufano (2011). "Financially fragile households: evidence and implications." Working paper, NBER Working Paper 17072.

Mishel, Lawrence, Jared Bernstein, and Sylvia Allegretto (2007). The State of Working America 2006/2007. Ithaca, NY: Cornell University Press.

Mishel, Lawrence and Natalie Sabadish (2012, May). "CEO pay and the top 1 percent: how executive compensation and financial-sector pay have fueled income inequality." Issue brief 331, Economic Policy Institute.

Mohun, Simon (2006). "Distributive shares in the US economy, 1964-2001." Cambridge Journal of Economics 30(3), 347-370.

Onaran, Özlem, Engelbert Stockhammer, and Lukas Grafl (2011). "Financialisation, income distribution and aggregate demand in the USA." Cambridge Journal of Economics 35, $637-661$.

Palley, Thomas I. (2002). "Economic contradictions coming home to roost? does the us economy face a long-term aggregate demand generation problem?" Journal of Post Keynesian Economics 25, 9-32. 
Palley, Thomas I. (2012). "Wealth and wealth distribution in the neo-kaleckian growth model." Journal of Post Keynesian Economics 34, 449-70.

Palley, Thomas I. (2013a). "A Kaldor-Hicks-Goodwin-Tobin-Kalecki model of growth and distribution." Metroeconomica 64(2), 319345.

Palley, Thomas I. (2013b). "The middle class in macroeconomics and growth theory: a three class neo-kaleckian-goodwin model." Paper presented at the Meetings of the Eastern Economic Association, New York, May 2013.

Palma, José Gabriel (2009). "The revenge of the market on the rentiers. why neo-liberal reports of the end of history turned out to be premature." Cambridge Journal of Economics 33, 829869 .

Pasinetti, Luigi L. (1962). "Rate of profit and income distribution in relation to the rate of economic growth." Review of Economic Studies 29, 267-79.

Piketty, Thomas and Emmanuel Saez (2003, February). "Income inequality in the United States, 1913-1998." Quarterly Journal of Economics 118(1), 1-39.

Ravina, Enrichetta (2007). "Habit formation and keeping up with the Joneses: evidence from micro data." http://ssrn.com/abstract=928248.

Robinson, Joan (1962). Essays in the theory of economic growth. New York, New York: St Martin's press.

Schor, Juliet B. (1998). The Overspent American: Upscaling, Downshifting, and the New Consumer (1st ed.). New York, NY: Basic Books.

Setterfield, Mark (2013). "Wages, demand and us macroeconomic travails: Diagnosis and prognosis." In Steve M. Fazzari Cynamon, Barry Z. and Mark Setterfield, eds., After the Great Recession: The Struggle for Economic Recovery and Growth, pp. 158-184. Cambridge University Press. 
Setterfield, Mark and Andrew Budd (2011). "A Keynes-Kalecki model of cyclical growth with agent-based features." In Philip Arestis, ed., Microeconomics, Macroeconomics and Economic Policy: Essays in Honour of Malcolm Sawyer, pp. 228-50. London: Palgrave Macmillan.

Skott, Peter and Soon Ryoo (2008). "Macroeconomic implications of financialization." Cambridge Journal of Economics 32(?), 827-862.

Stockhammer, Engelbert (1999). "Robinsonian and kaleckian growth. an update on postkeynesian growth theories." Working Paper 67, Vienna University of Economics and Business Administration. http://ideas.repec.org/p/wiw/wiwwuw/wuwp067.html.

Wisman, Jon D. (2009). "Household saving, class identity, and conspicuous consumption." Journal of Economic Issues XLIII(1), 89-114.

Wisman, Jon D. (2013). "Wage stagnation, rising inequality and the financial crisis of 2008." Cambridge Journal of Economics 37, 921-945.

Wolff, E. N. (2010). "Recent trends in household wealth in the United States: rising debt and the middle-class squeeze - an update to 2007.” Levy Economics Institute Working Paper No. 589.

Wolff, Edward N. and Ajit Zacharias (2009). "Household wealth and the measurement of economic well-being in the united states." Journal of Economic Inequality 7, 83-115. 


\section{A Analysis of Debt Dynamics}

From the definition of $d_{R}$, we see that:

$$
\begin{aligned}
\dot{d}_{R} & =\frac{\beta\left(C^{T}-C_{W}\right)-\dot{D_{W}}}{K}-g_{K} d_{R} \\
& =\beta\left(\eta C_{R} / K-C_{W} / K\right)-\dot{D_{W}} / K-g_{K} d_{R} \\
& =\beta \eta c_{\pi}\left(\omega_{r} u+\pi u+i d_{R}\right)-\left(1+\beta c_{W}-c_{W}\right) \omega_{p} u+i d_{R}-g_{K} d_{R}
\end{aligned}
$$

After substituting the solutions of $u$ and $g_{K}$ into the above equation, we find that the debt dynamics of our model yield the following steady states:

$$
\begin{aligned}
d_{R 1}= & \frac{1}{2 c_{\pi} i \kappa_{r} \pi(1+\beta \eta)}\left\{\kappa_{0}\left[-1+c_{W} \omega_{p}(1-\beta)+c_{\pi}(1+\beta \eta)\left(\pi+\omega_{p} \alpha \phi\right)\right]\right. \\
& +i\left[1-\kappa_{r} \pi+c_{W} \omega_{p}(\beta-1)+c_{\pi}^{2} \beta \eta(1+\beta \eta)\left(\omega_{r}-\omega_{p} \alpha \phi\right)-c_{\pi}\left[\pi-\beta \eta+\left(1+\kappa_{r}\right) \pi \beta \eta\right.\right. \\
& \left.\left.+\omega_{p}\left(c_{W}(\beta-1)+(1+\beta \eta)(1+\alpha \phi)\right)\right]\right] \\
& +\sqrt{\{4} c_{\pi} i \kappa_{0} \kappa_{r} \pi(1+\beta \eta)\left[\omega_{p}\left(-1+c_{W}-c_{W} \beta\right)+c \pi\left(\pi+\omega_{r}\right) \beta \eta\right] \\
& +\left[-\kappa_{0}+\kappa_{0}\left[-c_{W} \omega_{p}(\beta-1)+c_{\pi}(1+\beta \eta)\left(\pi+\omega_{p} \alpha \phi\right)\right]+i\left[1-\kappa_{r} \pi+c_{W} \omega_{p}(\beta-1)\right.\right. \\
& \left.\left.\left.\left.+c_{\pi}^{2} \beta \eta(1+\beta \eta)\left(\omega_{r}-\omega_{p} \alpha \phi\right)-c_{\pi}\left[\pi-\beta \eta+\left(1+\kappa_{r}\right) \pi \beta \eta+\omega_{p}\left[c_{W}(\beta-1)+(1+\beta \eta)(1+\alpha \phi)\right]\right]\right]\right]^{2}\right\}\right\}
\end{aligned}
$$




$$
\begin{aligned}
d_{R 2}= & \frac{1}{2 c_{\pi} i \kappa_{r} \pi(1+\beta \eta)}\left\{\kappa_{0}\left[-1+c_{W} \omega_{p}(1-\beta)+c_{\pi}(1+\beta \eta)\left(\pi+\omega_{p} \alpha \phi\right)\right]\right. \\
& +i\left[1-\kappa_{r} \pi+c_{W} \omega_{p}(\beta-1)+c_{\pi}^{2} \beta \eta(1+\beta \eta)\left(\omega_{r}-\omega_{p} \alpha \phi\right)-c_{\pi}\left[\pi-\beta \eta+\left(1+\kappa_{r}\right) \pi \beta \eta\right.\right. \\
& \left.\left.+\omega_{p}\left(c_{W}(\beta-1)+(1+\beta \eta)(1+\alpha \phi)\right)\right]\right] \\
& -\sqrt{\{4} 4 c_{\pi} i \kappa_{0} \kappa_{r} \pi(1+\beta \eta)\left[\omega_{p}\left(-1+c_{W}-c_{W} \beta\right)+c \pi\left(\pi+\omega_{r}\right) \beta \eta\right] \\
& +\left[-\kappa_{0}+\kappa_{0}\left[-c_{W} \omega_{p}(\beta-1)+c_{\pi}(1+\beta \eta)\left(\pi+\omega_{p} \alpha \phi\right)\right]+i\left[1-\kappa_{r} \pi+c_{W} \omega_{p}(\beta-1)\right.\right. \\
& \left.\left.\left.\left.+c_{\pi}^{2} \beta \eta(1+\beta \eta)\left(\omega_{r}-\omega_{p} \alpha \phi\right)-c_{\pi}\left[\pi-\beta \eta+\left(1+\kappa_{r}\right) \pi \beta \eta+\omega_{p}\left[c_{W}(\beta-1)+(1+\beta \eta)(1+\alpha \phi)\right]\right]\right]\right]^{2}\right\}\right\}
\end{aligned}
$$

The stability of the equilibria is examined as follows:

$$
\begin{aligned}
\left.\frac{\partial \dot{d_{R}}}{\partial d_{R}}\right|_{d_{R}=d_{R 1}}= & \frac{1}{-1+\kappa_{r} \pi+c_{W} \omega_{p}(1-\beta)+c_{\pi}(1+\beta \eta)\left(\pi+\omega_{p} \alpha \phi\right)} \\
& \sqrt{\{} 4 c_{\pi} i \kappa_{0} \kappa_{r} \pi(1+\beta \eta)\left[\omega_{p}\left(-1+c_{W}-c_{W} \beta\right)+c \pi\left(\pi+\omega_{r}\right) \beta \eta\right] \\
& +\left[-\kappa_{0}+\kappa_{0}\left[-c_{W} \omega_{p}(\beta-1)+c_{\pi}(1+\beta \eta)(\pi+\omega \alpha \phi)\right]\right. \\
& +i\left[1-\kappa_{r} \pi+c_{W} \omega_{p}(\beta-1)+c_{\pi}^{2} \beta \eta(1+\beta \eta)\left(\omega_{r}-\omega_{p} \alpha \phi\right)\right. \\
& \left.\left.\left.-c_{\pi}\left(\pi-\beta \eta+\left(1+\kappa_{r}\right) \pi \beta \eta+\omega_{p}\left(c_{W}(\beta-1)+(1+\beta \eta)(1+\alpha \phi)\right)\right)\right]\right]^{2}\right\} \\
\left.\frac{\partial \dot{d}_{R}}{\partial d_{R}}\right|_{d_{R}=d_{R 2}=} & \\
& -1+\kappa_{r} \pi+c_{W} \omega_{p}(1-\beta)+c_{\pi}(1+\beta \eta)\left(\pi+\omega_{p} \alpha \phi\right) \\
& \sqrt{\left\{4 c_{\pi} i \kappa_{0} \kappa_{r} \pi(1+\beta \eta)\left[\omega_{p}\left(-1+c_{W}-c_{W} \beta\right)+c \pi\left(\pi+\omega_{r}\right) \beta \eta\right]\right.} \\
& +\left[-\kappa_{0}+\kappa_{0}\left[-c_{W} \omega_{p}(\beta-1)+c_{\pi}(1+\beta \eta)(\pi+\omega \alpha \phi)\right]\right. \\
& +i\left[1-\kappa_{r} \pi+c_{W} \omega_{p}(\beta-1)+c_{\pi}^{2} \beta \eta(1+\beta \eta)\left(\omega_{r}-\omega_{p} \alpha \phi\right)\right. \\
& \left.\left.\left.-c_{\pi}\left(\pi-\beta \eta+\left(1+\kappa_{r}\right) \pi \beta \eta+\omega_{p}\left(c_{W}(\beta-1)+(1+\beta \eta)(1+\alpha \phi)\right)\right)\right]\right]^{2}\right\}
\end{aligned}
$$

